\title{
Classifying Worker Types in the U.S. Labor Market
}

Victoria Gregory, Economist

Guido Menzio, Professor of Economics, New York University

David Wiczer, Assistant Professor of Economics, Stony Brook University

W orkers experience all sorts of trajectories in the labor market as they cycle through various jobs and weather unemployment spells. What systematic patterns in employment histories do we see in U.S. data? Our recent paper (Gregory, Menzio, and Wiczer, 2021) documents the existence of several types of workers who are differently affected by job loss and by the onset of a recession. ${ }^{1}$ Classifying workers in this way can help resolve several puzzles in economics related to labor market dynamics.

We use data from the Census Bureau's Longitudinal Employer-Household Dynamics program to classify workers by their labor market histories. This dataset consists of a random sample of employment records from 1997 to 2014 and contains about 692,000 workers after applying our selection criteria. In each quarter, we observe each worker's earnings; demographic information, such as age and sex; employer identifiers; and how long the worker has been employed in each job. We can also infer the timing and length of unemployment spells.

We measure each worker's job durations, unemployment durations, fraction of time spent in unemployment, and number of jobs held over the sample period. We use machine learning to classify workers into worker types based on the characteristics noted above. ${ }^{2}$

The table summarizes the characteristics of each of our three worker types, which we call alphas, betas, and gammas. Alpha workers are 57 percent of the labor force-the largest

\section{Descriptive Statistics for Each Worker Type}

\begin{tabular}{|c|c|c|c|}
\hline & Alpha workers & Beta workers & Gamma workers \\
\hline Population share & $57.0 \%$ & $26.0 \%$ & $17.0 \%$ \\
\hline \multicolumn{4}{|l|}{$\%$ of jobs lasting } \\
\hline$<1$ quarter & $13.9 \%$ & $20.1 \%$ & $39.0 \%$ \\
\hline 1-4 quarters & $18.7 \%$ & $23.3 \%$ & $32.1 \%$ \\
\hline 5-8 quarters & $23.6 \%$ & $23.8 \%$ & $19.1 \%$ \\
\hline$>8$ quarters & $43.9 \%$ & $32.9 \%$ & $11.9 \%$ \\
\hline \multicolumn{4}{|c|}{$\%$ of unemployment spells lasting } \\
\hline$<1$ quarter & $79.4 \%$ & $39.0 \%$ & $55.3 \%$ \\
\hline 1-4 quarters & $15.7 \%$ & $55.8 \%$ & $31.5 \%$ \\
\hline 5-8 quarters & $4.9 \%$ & $5.2 \%$ & $13.3 \%$ \\
\hline$\%$ of time spent unemployed & $3.6 \%$ & $9.6 \%$ & $29.2 \%$ \\
\hline $\begin{array}{l}\text { Average quarterly earnings } \\
\text { (2007 dollars) }\end{array}$ & $\$ 11,050$ & $\$ 7,376$ & $\$ 5,370$ \\
\hline \multicolumn{4}{|l|}{ Demographics } \\
\hline Average birth year & 1963 & 1964 & 1967 \\
\hline$\%$ female & $47.9 \%$ & $48.6 \%$ & $46.3 \%$ \\
\hline$\%$ some college & $62.0 \%$ & $55.9 \%$ & $49.6 \%$ \\
\hline
\end{tabular}


share-while betas and gammas are 26 percent and 17 percent, respectively.

The table shows that alphas have the longest job durations and the shortest unemployment spells. Specifically, almost half of their job spells last longer than two years and the vast majority of their unemployment spells last less than a quarter. They are unlikely to experience longterm unemployment, with only about 5 percent of alpha unemployment spells lasting between one and two years. In addition, they are the highest earners. On average, alphas make 1.5 times more than betas and 2 times more than gammas.

\section{Why some worker types have difficulty finding stable jobs can't easily be explained by demographic characteristics.}

In contrast, gammas have the shortest job durations of the three groups, the longest unemployment spells, and the lowest wages. Only about 12 percent of gammas' job spells last more than two years, and over one-third last less than one quarter. They are also much more likely to experience long-term unemployment spells; the average gamma in our sample spends nearly 30 percent of their time unemployed. Betas fall in between alphas and gammas along these dimensions. They tend to have shorter job durations than alphas but spend less time unemployed than gammas.

We also examine the observable characteristics of each type of worker. The three worker types are similar in age; the average birth year is 1963 for alphas, 1964 for betas, and 1967 for gammas. The fraction of women is also similar: 48 percent for alphas, 49 percent for betas, and 46 percent for gammas. We do find more variation in terms of education level: 62 percent of alphas, 56 percent of betas, and 50 percent of gammas have at least some college education. However, none of these group-level averages is far from the 58 percent average for the full sample. This finding suggests that an individual's classification as an alpha, beta, or gamma cannot be easily explained by demographic characteristics such as age, gender, or education level.
In conclusion, these results show that there is a large group of workers who tend to remain in stable employment for most of their lives (the alphas), a smaller group of workers who have shorter job spells but are unlikely to be stuck in unemployment for a long time (the betas), and an even smaller group of workers who are the least likely to hold stable jobs and most likely to become long-term unemployed (the gammas). The earnings for each of the three groups are similarly ordered, with alphas earning the most, betas the next most, and gammas the least.

Our results also show that going beyond observable dimensions better identifies how employment patterns differ among workers. More broadly, identifying which groups are least likely to be in stable employment is important for understanding a variety of labor market phenomena (Hall and Kudlyak, 2019; Ahn and Hamilton, 2020; and Gregory, Menzio, Wiczer 2021). For instance, the sharp rise and slow recovery of the unemployment rate during the Great Recession are related to the types of workers present in the labor market. These differences can also help explain why it can take a long time for a worker's earnings to recover following a job loss.

\section{Notes}

1 The research in this essay and in Gregory, Menzio, and Wiczer (2021) use data from the Census Bureau's Longitudinal Employer Household Dynamics program, which was partially supported by National Science Foundation grants SES-9978093, SES-0339191, and ITR-0427889; National Institute on Aging grant AG018854; and grants from the Alfred P. Sloan Foundation.

2 For the technically minded, note that we employ a machine learning method known as k-means clustering to assign workers to groups of similar workers.

\section{References}

Ahn, Hie Joo and Hamilton, James D. "Heterogeneity and Unemployment Dynamics." Journal of Business \& Economic Statistics, 2020, 38(3), pp. 554-69.

Gregory, Victoria; Menzio, Guido and Wiczer, David G. "The Alpha Beta Gamma of the Labor Market." NBER Working Paper No. 28663, National Bureau of Economic Research, 2021; https://www.nber.org/papers/w28663.

Hall, Robert E. and Kudlyak, Marianna "Job-Finding and Job-Losing: A Comprehensive Model of Heterogeneous Individual Labor-Market Dynamics." NBER Working Paper No. 25625, National Bureau of Economic Research, 2019; https://www.nber.org/papers/w25625. 